\title{
Razvojne značilnosti otrok v okviru forenzičnega razgovora
}

\author{
Tinkara Pavšič Mrevlje* \\ Fakulteta za varnostne vede, Univerza v Mariboru
}

\begin{abstract}
Povzetek: Otroci so v sodnih procesih lahko adekvatne priče, če je forenzični intervju ustrezno izpeljan. Prispevek predstavlja pomembnejše linije otrokovega razvoja - mišljenje, spomin, govor in socialno-emocionalni razvoj - in jih povezuje z usmeritvami za vodenje razgovora $z$ otrokom. Zaradi pogostega prepričanja, da je otroka mogoče pripraviti do neresničnega pričanja in da ne loči med realnim ter domišljijskim, sta obravnavani tudi temi laganja in sugestibilnosti. Prispevek na koncu daje nekatere praktične usmeritve za izvedbo forenzičnega razgovora in opozarja na pomen izobraževanja vseh, ki so v stiku $\mathrm{z}$ otroki - potencialnimi pričami.
\end{abstract}

Ključne besede: forenzično ocenjevanje, intervju, otroci, priče, spomin, sugestibilnost

\section{Children's developmental characteristics in the forensic interview}

\author{
Faculty of Criminal Justice and Security, University of Maribor, Slovenia
}

\begin{abstract}
Children can be credible witnesses in court procedures given an adequately conducted forensic interview with them. This paper presents the most important features of a child's development (the cognitive and socioemotional development and the development of language and communication) and from these features derives the specific guidelines for forensic interviews of children. Due to the frequent belief that children can be led to false witnessing and that they do not differentiate between reality and fantasy the topics of lying and suggestibility are also discussed. At the end some practical suggestions are given with recommendations for trainings of all professionals working with children that are potential witnesses.
\end{abstract}

Keywords: forensic evaluation, interview, children, witnesses, memory, suggestibility

\footnotetext{
"Naslov/Address: Tinkara Pavšič Mrevlje, Fakulteta za varnostne vede, Univerza v Mariboru, Kotnikova 8, 1000 Ljubljana, e-pošta: tinkara.pavsicmrevlje@fvv.uni-mb.si

Članek je licenciran pod pogoji Creative Commons Attribution 4.0 International licence. (CC-BY licenca).

The article is licensed under a Creative Commons Attribution 4.0 International License (CC-BY license).
} 
V zadnjih 50. letih so različne oblike nasilja nad otroki (psihično, telesno, spolno) pogosto predmet pogovorov in raziskav. Zdaj je jasno, da so otroci v sodnih postopkih lahko adekvatne priče, treba je le upoštevati njihove razvojne značilnosti. V ZDA je v 90. letih preteklega stoletja nekaj odmevnih primerov pritegnilo pozornost raziskovalcev, saj so neprimerne tehnike izpraševanja kompromitirale in kontaminirale pričanje otrok, ki je bilo zato nezanesljivo in pomanjkljivo.

Raziskave kažejo, da se otroci lahko spomnijo dogodkov, ki so jih doživeli, kljub temu pa je odnos med starostjo in spominom kompleksen; na kvaliteto danih informacij namreč vpliva veliko dejavnikov. C. M. Tang (2006) piše, da so ključne usmeritve glede intervjuvanja malčkov vezane na njihovo sposobnost besedne komunikacije, kar v povprečju pomeni starost tri leta. Pri tem je pomembno tudi, da se je dogodek, o katerem bo govora, zgodil po drugem letu starosti, da bi ga otroci zmogli opisati v povezanih stavkih.

$\mathrm{Na}$ drugi strani je $\mathrm{z}$ vidika forenzičnega intervjuja pomemben dejavnik tudi izpraševalčeva zmožnost, da izvabi informacije iz otroka. Ni treba posebej poudarjati, da je govora o informacijah, ki izvirajo iz otrokove izkušnje, in ne tistih, ki bi jih izpraševalec želel slišati. Zmožnost pripraviti otroka, da jih izrazi, temelji na poznavanju njegovih razvojnih značilnosti: predvsem sposobnosti komunikacije, spomina in mišljenja. Zato prispevek povzema potek otrokovega razvoja na pomembnejših področjih in ob tem opozarja na značilnosti, pomembne za preiskovalni intervju. Seveda je delitev na podpoglavja prisiljena, saj se posamezni vidiki otrokovega delovanja povezujejo in prekrivajo, a jih je ločene lažje razumeti.

\section{Razvoj mišljenja}

$\mathrm{Z}$ razvojem mišljenja od konkretnega $\mathrm{k}$ vse bolj abstraktnemu je otrok vedno bolj sposoben misel odcepiti od predmeta ali dejanja. Tako premosti omejitve trenutnega doživljanja, lahko se obenem ukvarja s preteklostjo, sedanjostjo in prihodnostjo ter sestavlja koncepte po svoji volji. To omogočata tudi razvoj govora, zlasti otrokova raba besed. $Z$ besedo kot simbolom (abstraktni nivo) otrok namreč poimenuje nek predmet, osebo, dejanje (konkretni nivo).

Sprva je otrokovo mišljenje konkretno, Piaget (po Marjanovič Umek, 2004) trdi, da gre za t. i. predoperativno mišljenje (3-6 let), ki je logično in organizirano, dokler je vezano na konkretno informacijo, ki jo neposredno zaznava. Abstraktne ideje, ki niso očitne v realnem svetu, otroku te starosti delajo težave, zato bo $\mathrm{v}$ razgovoru uporabljene besede zelo konkretno razumel (Lamb, Hershkowitz, Orbach in Esplin, 2008). Če ga, na primer, vprašamo, kaj se je zgodilo v njihovem stanovanju, otrok pa z družino živi v hiši, morda na vprašanje sploh ne bo odgovoril.

Otrok je v tem obdobju egocentričen (usmerjen v svoje zaznavanje in mišljenje), v preprostih situacijah že zna zavzeti perspektivo drugega in je empatičen (Marjanovič
Umek, 2004), a zanj ta naloga ni lahka. Če malčka vprašamo »Te je gospa videla?«, lahko dobimo pritrdilen odgovor zato, ker je on videl gospo; če je ona res videla njega, pa pravzaprav ne ve (Wilson in Powell, 2001). Otrok je namreč šele okoli četrtega leta sposoben razumeti, da so njegova lastna mentalna stanja lahko različna od mentalnih stanj drugih. Perner (1990, v Marjanovič Umek, 2004) to poimenuje reprezentacijska teorija uma, razvoj katere otroku omogoča tudi razumevanje, da ima nekdo o realnosti napačno prepričanje.

Pri malčkih se razvijata tudi pojma prostor in čas, a so jim abstraktni koncepti, na primer enote, težje razumljivi. Vprašanja, ki se na primer tičejo starosti, višine, teže, je treba zato postaviti premišljeno, najbolje je tovrstne podatke dobiti s pomočjo primerjave: otrok bo lažje odgovoril, ali je bila oseba visoka (oziroma kako visoka), če jo bo primerjal z nekom, ki ga pozna (Wilson in Powell, 2001). Podobno je s časom; ne le zato, ker gre za abstrakten koncept, temveč tudi zato, ker ga pri različni starosti različno zaznavamo. Malčke je zato veliko bolje kot »Kdaj se je to zgodilo? Koliko časa je trajalo?« vprašati na primer »Si bil takrat v vrtcu ali šoli? Ste takrat živeli v starem ali v novem stanovanju?« (Wilson in Powell, 2001).

V obdobju operativnega mišljenja (7-11 let) je otrok decentriran, razume reverzibilnost, mišljenje je bolj logično. Pri enajstih letih otrok razvije abstraktno, znanstveno mišljenje (formalno mišljenje), torej sklepa, posplošuje, preverja hipoteze. Razumevanje časa je že boljše, zato (bolje) razume koncepte prej, medtem, potem in lahko ga vprašamo »Je bilo to pred tvojim rojstnim dnevom ali po njem?« ali »Se je to zgodilo pred zimskimi počitnicami, med njimi ali pozneje?« (Wilson in Powell, 2001). Do osmega leta imajo otroci tudi težave pri razumevanju čustvenih konceptov (Aldridge in Wood, 1997). Otroci v zgodnjem otroštvu pozitivna čustva izražajo predvsem kot veselje, negativna pa kot žalost. Jezo, strah in tesnobo razumejo šele osemletniki.

Otroci že zelo zgodaj razlikujejo med živim in neživim svetom, domišljijsko mišljenje pa je prisotno dlje časa. A kaj domišljijsko (magično) pravzaprav pomeni? Je to verovanje $\mathrm{v}$ čarobno ali zgolj beseda za kompleksne in nepoznane, a mogoče fizične vplive (Subbotsky, 2010)? Triletniki že razlikujejo med realnim psom in psom iz sanj, a je včasih meja med domišljijo in resničnostjo kljub temu zabrisana. Malčki se namreč včasih vedejo, kot da imaginarna bitja res obstajajo (Papalia, Olds in Feldman, 2003). A pregled literature kaže, da domišljijsko mišljenje ni posledica nesposobnosti razlikovanja med domišljijo in realnostjo, temveč je magično vse tisto, česar otroci ne morejo razumeti (Papalia idr., 2003).

\section{Razvoj govora in komunikacijskih spretnosti}

Komunikacijske spretnosti so pomembne zato, da v razgovoru $\mathrm{z}$ otrokom pridobimo potrebne informacije, seveda prave in natančne. Otrokovo razumevanje jezika 
se začne $\mathrm{s}$ preverbalnim razumevanjem - prozodijo (intonacija, čustvena spremljava in vedenje ob govoru), čeprav temu enakovrednega izražanja dojenček in pozneje malček še ne zmoreta. Dejstvo, da razvoj izražanja zaostaja za razvojem razumevanja tudi pozneje, je pogosto nepoznano in je malček zato lahko izpostavljen neustreznim situacijam in pogovorom (Garber, 2009).

Proces razvoja govora je od razvoja kognitivnih sposobnosti neločljiv, čeprav ga tu zaradi lažjega razumevanja obravnavamo ločeno. Govor je namreč vezan na razvoj višjih nivojev izvršitvenih funkcij in najbrž celo potreben za njihov razvoj. Študije kažejo, da so govorne sposobnosti vezane na prilagodljivost in delovni spomin ter da vzpostavljajo izvršitvene funkcije (Müller, Jacques, Brocki in Zelazo, 2009). Govor je pomembno vezan tudi na socialni razvoj; pravzaprav se funkcije govora kot dejavnosti, socialnega razumevanja in kot socialne interakcije medsebojno prepletajo (Carpendale, Lewis, Susswein in Lunn, 2009).

Jok je edini način komunikacije novorojenčka. Med šestim tednom in tretjim mesecem otrok gruli, med tretjim in šestim mesecem posnema glasove, ki jih sliši, bebljanje pa se pojavi nekje med šestim in desetim mesecem. Okoli desetega meseca upade zaznavanje in proizvajanje glasov, neznačilnih za kulturno okolje/materni jezik (Papalia idr., 2003). Iz celotnega spektra zvokov, skupnega različnim etničnim (in govornim) skupinam, se ohranijo zvoki jezika, ki jih otrok sliši v stiku z ljudmi v svojem okolju (Midaeva \& Lyubimova, 2008).

Prvo besedo otrok izreče nekje med desetim in štirinajstim mesecem. Takrat $\mathrm{z}$ besednim izražanjem prenaša pomen. Med osemnajstim in štiriindvajsetim mesecem otrok sestavlja prve stavke. Najprej je njegovo izražanje (ne pa tudi razumevanje!) poenostavljeno, omejeno na konkretne predmete (»avto« je le določena igrača) ali posplošeno glede na nekatere podobnosti (vse živali s štirimi nogami so »psi«) in ne izraža slovničnih razmerij (Papalia idr., 2003). V tem času se besedišče s 50 besed razširi na 400 besed. V razgovorih, kjer je vsaka informacija lahko bistvenega pomena, se moramo zavedati, da otroci pogosto uporabljajo besede, katerih pomen jim ni znan ali pa je idiosinkratičen (Garber, 2009). Zato se je pomembno prepričati, kaj otrok, ko na primer uporabi besedo »spolnost « ali »dotik«, s tem sploh misli; še posebej takrat, ko določeno besedo otrok uporablja na rigiden način in $\mathrm{v}$ omejenem kontekstu. Preiskovalec namreč lahko preceni otrokove verbalne sposobnosti in zato zastavlja vprašanja, ki so za otroka prezahtevna (Lamb idr., 2008). Omenjene komunikacijske sposobnosti, ki pri otroku še niso dokončno razvite, lahko povzročijo, da izpraševalec otrokove odgovore razume napačno. Ker napačno razumljenih informacij otroci po navadi ne korigirajo, se te skozi intervju ponavljajo in tako izkrivljajo spomin. Predvsem malčki namreč informacije, dobljene po dogodku (resnične in napačne), radi vključijo v svojo pripoved in odgovore (Hunt in Borgida, 2001).

Pri treh letih otrok uporablja od 900 do 1000 besed, do šestega leta jih usvoji približno 2600. Med petim in sedmim letom otrokov govor postane podoben govoru odraslih, povedi so zapletenejše, otrok uporablja veznike, člene in zložene povedi (Papalia idr., 2003). Pomembno je torej, da se izpraševalec zaveda, da če malček razume posamezne besede, še ni rečeno, da jih bo razumel povezane v povedi. Izpraševalec se mora izogibati starosti neprimernim besedam, stavčnim strukturam (negacije trditev ali potrditev večplastnih vprašanj »Ali ni res, da ...«) in konceptom (prej, včeraj, nekaj, katerikoli). Tako zastavljenih vprašanj otrok v večini primerov ne razume, kar pa je še pomembnejše, svojega nerazumevanja se sploh ne zaveda (Lamb idr., 2008). Malčki tudi še ne razumejo širšega konteksta vprašanja »Ali veš, zakaj si tu?« in zaradi slabše razvitih metajezikovnih sposobnosti pri odgovarjanju informacije še ne znajo podati smiselno zaokroženo in preverjati, ali so pravilno razumljeni (Lamb idr., 2008). Metajezikovno zavedanje, ki omogoča razmišljanje o jeziku kot sistemu, se začne razvijati sicer že v zgodnjem otroštvu, pomembne razvojne korake na tem področju pa otrok naredi med četrtim in osmim letom (Berk, 2006). Te primanjkljaje je mogoče z ustreznimi tehnikami izpraševanja izboljšati tako, da otrok dobi jasna navodila o vlogi izpraševalca (ki ni seznanjen $\mathrm{z}$ vsemi podrobnostmi dogodka), da se lahko z njim ne strinja, kvaliteto otrokove pripovedi pa izboljšajo tudi izkušnje $\mathrm{s}$ podajanjem natančnih pripovedi (Lamb in Brown, 2006).

Usvojene spretnosti komunikacije brez dvoma vplivajo na otrokovo jasnost in celostnost odgovorov pri pričanju. Predvsem je treba biti pozoren na neskladje med dejansko in navidezno usvojenimi spretnostmi. Ob omenjenih prilagoditvah, ki jih je treba upoštevati pri vodenju razgovora predvsem $\mathrm{z}$ otroki $\mathrm{v}$ zgodnjem otroštvu, pa je smiselno poudariti, da so tudi triletniki sposobni opisati svoje izkušnje in odgovoriti na veliko število vprašanj (Hershkowitz, Orbach, Lamb, Katz in Horowitz, 2012).

Razvoj govora je odvisen tudi od drugih dejavnikov, na primer spola ali okolja, v katerem otrok živi. Garber (2009) zapiše, da bomo najverjetneje največ informacij dobili od deklic prvorojenk iz bolje situiranih družin, ki imajo pozorne matere. Pri otrocih, ki so bili v zgodnjih letih razvoja zlorabljeni in/ali zanemarjani, pa je potrebna še posebna pozornost, saj tovrstne specifične okoliščine vplivajo na razvoj možganov (Perry in Pollard, 1997), torej zagotovo tudi na razvoj govora.

\section{Spomin}

Da bi otrok lahko podal natančno informacijo, jo mora biti sposoben priklicati iz spomina. Zato je bistveno, da vemo, česa se otroci različnih starosti lahko spomnijo o pomembnih dogodkih, sploh če so se zgodili že pred časom. Pri tem moramo upoštevati vse dejavnike, ki vplivajo na vkodiranje, priklic in podajanje informacije (Ornstein in Haden, 2002).

Preden lahko katerokoli informacijo vkodiramo in ohranimo v spominu, jo moramo najprej zaznati in se nanjo osredotočiti. Težave spominjanja namreč niso nujno težave priklica, saj se vsebine morda sploh niso 
vkodirale v spominski sistem. Starejši kot je otrok, večja je učinkovitost pri usmerjanju in ohranjanju pozornosti, delno tudi zaradi zorenja živčnega sistema (Shaffer in Kipp, 2010). Malčki se usmerjajo predvsem na dražljaje, ki so jim ljubi ali prevladujejo, z leti pa otroci postajajo boljši pri selektivni pozornosti in inhibitornih procesih (osredotočenost na pomembne dražljaje in ignoriranje drugih šumov, nepomembnih informacij).

Z izboljšanjem pozornosti so učinkovitejše tudi strategije shranjevanja informacij v dolgoročni spomin: ponavljanje, organizacija in obdelava podatkov. Pri otrocih okoli sedmega in osmega leta sta ponavljanje in organizacija manj učinkovita, ker ponavljajo po delih in podatke organizirajo predvsem po asociacijah - pozneje otrok uporabi abstraktnejše kategorije in priklic je boljši (Berk, 2006). Okoli desetega leta otrok začne uporabljati tudi obdelavo, ki vključuje ustvarjanje odnosa ali skupnega pomena med dvema ali več deli informacije, ki ne spadajo $\mathrm{v}$ isto kategorijo.

Ko je podatek enkrat $\mathrm{v}$ dolgoročnem spominu, ga moramo od tam znova pridobiti, da ga lahko uporabimo. Najpreprostejši način pridobivanja je prepoznava, saj je vsebina, ki naj bi jo priklicali, prisotna in nam služi kot namig. Že malčki tako lahko prepoznajo veliko število dražljajev. Veliko težji je priklic, ko se želimo spomniti čim več informacij, ne da bi nam pri tem pomagali kakršnikoli namigi. Štiriletnik pravilno prepozna okoli 90 odstotkov od 80 prikazanih slik, prikliče pa jih le nekaj (Berk, 2006).

Skript je posebna oblika rekonstruiranega spomina. Ko doživljamo ponavljajoče se dogodke, jih stopimo $\mathrm{v}$ eno reprezentacijo, pri čemer se posamezne razlike med dogodki izgubijo. Gre za t. i. epizodični spomin, ker so to vsakodnevne ali pogoste življenjske epizode (na primer jutranje vstajanje, obed $\mathrm{v}$ restavraciji, nakupovanje $\mathrm{v}$ trgovini). V spominu pa se shranijo tudi tiste reprezentacije enkratnih dogodkov, ki so osebnega pomena (selitev, rojstvo sorojenca). Govorimo o avtobiografskem spominu. Da bi otrok imel avtobiografski spomin, mora najprej imeti jasno podobo o sebi (ta se razvije okoli drugega leta). Takrat šele ve, da gre za dogodke, ki so se zgodile prav njemu - nato pa jih mora znati tudi integrirati v časovno organizirano življenjsko zgodbo (Berk, 2006). Do šestega leta postaja otrokov opis posebnih enkratnih dogodkov natančnejši ter bolje organiziran in ovrednoten (torej ima osebni pomen). Odnos in komunikacija med starši in otrokom imata pri tem pomembno vlogo; angažirani starši, ki izpopolnjujejo otrokove pripovedi in spomine opisujejo povezano ter s čustveno spremljavo, pripomorejo $\mathrm{k}$ bogatim spominom otroka (Fivush in Reese, 2002).

Večina ljudi se dogodkov iz svojega življenja pred tretjim letom ne spominja. Temu pojavu pravimo infantilna amnezija. Tako kot odrasli doživljajo tovrstno amnezijo tudi otroci. Vendar pa so najzgodnejši spomini malčkov zgodnejši v primerjavi s spomini otrok po šestem letu, saj otrok odrašča in pozablja (Peterson, 2012). Vzroki za infantilno amnezijo še niso popolnoma jasni. Med njimi so zorenje frontalnih možganskih režnjev, vpliv družinskih pogovorov na ohranjanje spominov, v katerih otrok lahko aktivno sodeluje šele okoli tretjega leta, in neučinkovite strategije priklica (Carter Imhoff in Baker-Ward, 2002).

Najzgodnejši spomini so neverbalni, t. i. implicitni, v forenzičnem intervjuju pa želimo pridobiti predvsem informacije, ki so del eksplicitnega spomina (Olafson, 2007), ki je zavesten, verbalen, pripoveden. Takrat je pomembno ugotoviti, kakšne so otrokove spominske kapacitete za shranjevanje in priklic vsebin. Jezik ima zagotovo pomembno vlogo pri priklicu najzgodnejših spominov. Kot v pregledu literature pišejo Lamb in drugi (2008), so krhki zgodnji spomini vkodirani le v neverbalni obliki in bi morali biti pretvorjeni v besede, da bi lahko bili priklicani.

Na spominske kapacitete pa vpliva tudi dejstvo, da imajo malčki manj splošnega znanja, v katerega naj bi umestili izkušnje, še nepopolno razvite sposobnosti mišljenja in slabše komunikacijske spretnosti (Ornstein in Haden, 2002).

Če gre za ponavljajoče se dogodke, na primer zlorabo, bo to okrepilo spomin $\mathrm{v}$ obliki skriptov, obenem pa oslabilo priklic posebnosti ali podrobnosti posameznega dogodka. Pri otrokovem opisu dogodka, npr. spolne zlorabe, je zato dobro vedeti, če se je zloraba zgodila več kot enkrat. Ni pa priporočljivo vprašati kolikokrat, saj je taka ocena težavna tudi za odrasle, otrok pa lahko zaradi ustrežljivosti ugiba in dodatno izgubi na kredibilnosti in kompetentnosti (Olafson, 2007). Če se je dogodek (na primer zloraba) zgodil večkrat, bo za izpraševalce informacija o posameznih dogodkih pomembna. Ker so nenavadni dogodki v zaporedju tistih, ki so si podobni, v spominu jasneje zarisani, je mogoče vprašati po drugačnih dogodkih, po zadnjem ali prvem, morda po najhujšem.

Vpliva stresnosti oziroma travmatičnosti dogodka/ dogodkov na priklic zaradi etičnosti ni mogoče ustrezno raziskati, kaže pa, da »zmeren« stres priklic izboljšuje, v preveliki meri pa ga onemogoča (Bahrick, Parker, Fivush in Levitt, 1998). Vsekakor je treba ob tem upoštevati tudi druge dejavnike: stresnost samega izpraševanja, $\mathrm{z}$ dogodkom povezani sram, zadrego, krivdo, zanikanje, pa seveda naravno pozabljanje kot tako, nenazadnje pa tudi dejstvo, da si vseh vsebin ne zapomnimo, še posebej, če niso bile v središču pozornosti. Lamb in drugi (2008) po pregledu raziskav in literature pišejo, da je razlikovanje med prepoznavo in priklicem velikega pomena tako pri otrocih kot odraslih. Otrokovi opisi dogodkov s prostim priklicem so sicer krajši in nepopolni, a natančnejši. Dodatne podatke in podrobnosti je moč pridobiti še $\mathrm{z}$ nadaljnjimi odprtimi vprašanji tipa »Povej mi še kaj o tem.«. Zaradi že omenjenih otrokovih komunikacijskih spretnosti je prepoznava pogosto uporabljana, kar pa za otroka pomeni večji pritisk ne glede na to, ali odgovor na vprašanje sploh pozna. Pri prepoznavi gre namreč za bolj neposredno postavljena vprašanja, ki resda spodbudijo celostnejše odgovore, a obenem večajo možnost sugestibilnosti (Quas, Goodman, Ghetti in Redlich, 2000). 


\section{Socialni in čustveni razvoj otroka}

S socialno-emocionalnim razvojem otrok oblikuje svoj način vzpostavljanja in ohranjanja medosebnih odnosov, kar je vezano tudi na spoznavanje in diferenciranje čustev. Skozi izkušnje s skrbniki - to so po navadi starši - se otrok uči verbalne in neverbalne komunikacije, o tem, ali bodo njegove potrebe in želje zadovoljene, ter o tem, ali bo potolažen, ko bo treba. O vsem tem govori navezanost, ki je dejaven, medsebojno močno naklonjen recipročen odnos med dvema osebama (Zupančič, 2004a). Varno navezani otroci iz izkušenj vedo, da bo njihov skrbnik odziven in občutljiv za njihove potrebe. Izogibajoče navezani otroci so se naučili, da je skrbnik relativno neodziven in pogosto nedosegljiv (Garber, 2009). Otroci z dezorganizirano navezanostjo izražajo največ ogroženosti (Zupančič, 2004a), saj svoje skrbnike pogosto doživljajo kot zastrašujoče, hladne in grobe, po drugi strani pa intenzivne in preplavljajoče (Garber, 2009).

Tip navezanosti vpliva na to, kako otrok oceni, vkodira, organizira in pozneje iz spomina prikliče svoje izkušnje (Lamb idr., 2008). Raziskava je namreč pokazala (Goodman, Quas, Batterman-Faunce, Riddlesberger in Kuhn, 1997), da na napačen priklic bolj kot stresnost samega dogodka vpliva tip navezanosti. Ta ima pomembno vlogo pri tem, kako stresno bo otrok doživel posamezno situacijo in kako natančno se je bo spomnil. Varno navezani otroci bodo naredili manj spominskih napak. Avtorji zaključijo, da se izogibajoče navezani otroci med stresnim dogodkom najbrž osredotočajo na iskanje občutka varnosti in zato informacij ne vkodirajo enako dobro kot varno navezani. Poleg tega je verjetnost razkritja večja, če otroka primarni skrbnik podpira (Lippert, Cross, Jones in Walsh, 2009).

V prvih mesecih življenja je izražanje čustev vezano predvsem na dva pola: ugodno (veselje) in neugodno (na primer na lakoto, mraz, preglasno okolje). Neugodje se sčasoma diferencira na jezo in žalost (med četrtim in šestim mesecem), $v$ drugi polovici prvega leta pa se pojavi tudi strah (Berk, 2006). V drugem letu starosti, ko se malček jasneje loči od okolja, se pojavijo čustva samozavedanja, ki se nanašajo na ugodno ali neugodno doživljanje in vrednotenje sebe (Zupančič, 2004b). To so sram, zadrega, krivda, zavidanje in ponos.

$\mathrm{V}$ forenzičnem razgovoru $\mathrm{z}$ otrokom je izpraševalec vedno pozoren na čustva, ki spremljajo otrokovo pripoved. Ker gre pogosto za sume zlorabe, se posebej osredotoča na otrokove strahove. Zato je dobro poznati za razvojno fazo oziroma otrokovo starost običajne strahove (tabela 1), da jih ne bi razumeli, na primer, kot znak zlorabe. Strahovi s starostjo najprej naraščajo, saj je otrok izpostavljen vedno več dražljajem, ki lahko vzbudijo strah (Kavčič in Fekonja, 2004). Najpogostejši so po četrtem letu, okoli sedmega leta pa začnejo upadati zaradi vedno večjih kognitivnih in prilagoditvenih sposobnosti (Jamison, n. d.).

\section{Laganje in resnica}

Otroci niso nič bolj nagnjeni $\mathrm{k}$ laganju kot odrasli (Ruck, 1996). Laganje otrok pa je še manj pogosto, če otrok obljubi, da bo govoril resnico (Evans in Lee, 2010).

Za razliko od splošnega prepričanja je možnost, da otrok govori resnico, nasprotno sorazmerna s starostjo. $\mathrm{Na}$ »uspešno« laganje namreč vplivajo različni socialni in kognitivni dejavniki, med drugim tudi izvršitvene funkcije in moralni razvoj (Talwar in Lee, 2008). Malček se mora laganja pravzaprav naučiti, kar se zgodi med četrtim in šestim letom. V tem obdobju je laž vsaka neresnica, tudi nenamerna: »Stara sem štiri in ne pet let. Lažeš!« (Wilson in Powell, 2001). Tudi t. i. prosocialno laganje (laganje v korist in pomoč drugim) je zanje sporno, manj negativno pa postane v obdobju začetka osnovne šole $(\mathrm{Xu}, \mathrm{Bao}, \mathrm{Fu}$, Talwar in Lee 2010). Šele pri osmih letih otrok popolnoma razume, da laganje vključuje namerno zavajanje. Torej ne gre le za izpuščanje nekaterih podatkov (na primer pri ohranjanju skrivnosti), temveč za namerno ustvarjanje neresnice.

Večina otrok med tretjim in osmim letom sicer že laže, da bi prikrila svojo napako, prekršek in podobno, vendar otroci šele $\mathrm{z}$ leti (zaradi kognitivnega razvoja) zmorejo biti pri tem tudi konsistentni - na primer, da začetno laž podprejo tudi z naknadnimi trditvami (Talwar in Lee, 2008). To so $\mathrm{v}$ eni od redkih raziskav $\mathrm{s}$ tega področja proučevali Quas, Davis, Goodman in Myers (2007), in sicer z otroki, starimi od štiri do sedem let. Ugotovili so, da so otroci te starosti v določenih socialnih situacijah že sposobni zavajanja. Po navodilih so poročali o neresničnem dogodku, pri odgovarjanju na različna vprašanja o dogodku pa so bili tudi konsistentni. A so bili manj natančni pri odgovarjanju na druga vprašanja, ne vezana na laž. Pomembna ugotovitev raziskave je bila tudi, da so bili otroci, ki so govorili resnico, pri tem pomembno manj natančni in manj konsistentni.

Za laganje je pomembna tudi otrokova zmožnost uravnavanja in izkazovanja čustev. Da bi otrok lahko povedal laž ali zadržal skrivnost, mora znati prikriti ali

Tabela 1. Običajni viri strahu pri predšolskih otrocih (prilagojeno po Jamison, $n$. d.)

\begin{tabular}{ll}
\hline Starost & Najpogostejši strahovi \\
\hline do 2. leta & ločitev od staršev, neznanci, strah pred padcem v stranišče \\
2. leto & zaradi domišljijske igre se lahko pojavijo strahovi tudi v poznanih in pred tem netežavnih situacijah \\
3. in 4. leto & tema, glasovi, maske, pošasti iz televizije, živali, biti sam, tatovi, strah pred poškodbo, izguba staršev \\
5. leto & tema, izguba staršev, strah pred telesno poškodbo, da se bo izgubil, grmenje, psi \\
6. in 7. leto & duhovi, čarovnice, naravne nesreče, izguba staršev, divje živali, strah pred poškodbo \\
\hline
\end{tabular}


prikazati láži »ustrezna« čustva. Triletniki že kažejo prve poskuse prikrivanja svojih čustev, a imajo otroci v prvih razredih osnovne šole še vedno težave prikriti čustva, ki jih doživljajo, in prav tako težko prikažejo tista, ki jih ne čutijo (Shaffer in Kipp, 2010).

S sposobnostjo laganja je povezana tudi zmožnost ohranjanja skrivnosti, kar je v razgovoru z otrokom pogosto ključnega pomena. Med četrtim in šestim letom otrok že zna zadržati skrivnost, a je pri tem zelo tog: vsebine ne pove prav nikomur. Ob vstopu v šolo pa otroci že nekoliko bolje razlikujejo, kdaj skrivnosti lahko razkrijejo in kdaj jih ne smejo. Pri devetih letih so pri tem že zelo podobni odraslim (Wilson in Powell, 2001).

\section{Sugestibilnost}

Sugestibilnost otroka se nanaša na stopnjo vplivanja različnih dejavnikov na otrokovo poročanje o dogodku. Dejavniki so socialni in/ali psihološki, delujejo lahko pred poročanjem ali po njem (London, 2001; Tang, 2006). Sugestibilnosti so izpostavljeni predvsem otroci $\mathrm{v}$ zgodnjem otroštvu (Lamb idr., 2008), za kar so ključni trije dejavniki (Saywitz in Lyon, 2002): prosti priklic je zanje veliko težji kot prepoznava, do odraslih in njihovih prepričanj so spoštljivi (in se zato trudijo odgovoriti na vsa vprašanja, čeprav ne poznajo odgovorov), malčki pa imajo tudi posebne težave pri prepoznavanju izvora svojih spominov (na primer, če se je nek dogodek resnično zgodil ali so mu o tem le pripovedovali).

Sugestibilni niso le direktivno vodeni razgovori. Warren, Woodall, Hunt in Perry (1996) so pri analizi transkriptov pogovorov z zlorabljenimi otroki namreč ugotovili, da so izpraševalci otroku redkokdaj povedali, da je »ne vem« ali »ne razumem« sprejemljiv odgovor. Pogosto so uporabljali vprašanja tipa da-ne in sami v pogovor vključevali informacije, ki jih otrok (še) ni razkril. Zaprta vprašanja, na katera je mogoče odgovoriti v enem stavku (ali le z da ali ne), so najbrž najpogostejša in najbolj prefinjena oblika sugestibilnosti (Poole in Lindsay, 2002). Predvsem malčki posledično dajejo manj natančne odgovore. Pogosto se zgodi tudi, da zaradi spoštovanja do izpraševalca otroci odgovor ugibajo, tovrstna vprašanja pa lahko spomin tudi izkrivijo, če ima otrok občutek, da so mu konfabulacije poznane, ker jih je doživel (in ne zato, ker so mu jih povedali - napaka pri prepoznavanju vira spomina).

Pomembno je vedeti, da so sugestibilni tako otroci kot odrasli, le stopnja sugestibilnosti je različna. Prav tako pa je tudi otrok $v$ različnih situacijah za sugestije različno dovzeten. Na zgoraj omenjene dejavnike mora biti pozoren vsak izpraševalec in jih torej ne gre razumeti kot razloge za zmanjšano zanesljivost otrokovega pričanja.

\section{Podpora pri vodenju razgovora}

Pregled razvojnih značilnosti otroka daje vpogled v tehnike vodenja razgovora, ki spodbujajo in omogočajo čim natančnejši in popolnejši priklic pomembnih dogodkov. Učinkovitost forenzičnega razgovora z otrokom pa lahko povečamo tudi z nekaterimi drugimi dejavniki in tehnikami. Tukaj omenimo le dve.

\section{Ustvarjanje odnosa}

Otrok mora $\mathrm{v}$ forenzičnem razgovoru velikokrat razkriti precej stresne informacije, ki pogosto pobujajo sram. Vedenje izpraševalca je za otroka lahko suportivno ali zastrašujoče, in prav ti dve skrajnosti sta najpogostejši (Saywitz in Lyon, 2002); zaradi pretirane podpore otrok želi ugajati in temu skladno priredi tudi odgovore na vprašanja, zastraševanje pa ima enake posledice, le da takrat zaradi otrokovega strahu.

$\mathrm{Na}$ začetku razgovora je najprej treba vzpostaviti odnos med otrokom in nepoznanim izpraševalcem. Vendar pa je raziskav na to temo za zdaj še relativno malo. Obstoječe kažejo, da začetno spoznavanje iz otroka v poznejšem razgovoru izvabi več informacij, da pa je predolga začetna faza lahko za razgovor slaba, ker zmanjša otrokovo pozornost in skrajša čas, potreben za pridobivanje bistvenih podatkov (Lamb idr., 2008).

\section{Uporaba anatomskih lutk}

Lutke so najboljši pripomoček v razgovoru z otroki, starimi od dve do šest let, čeprav se te uporabljajo v različne namene: lutka je lahko dobrodošla za tolažbo in lažji začetek pogovora, kot anatomski model, za pomoč pri prikazovanju ali kot pripomoček pri spodbujanju spominov (Zorić, 2008). Raziskave o uporabi lutk ne dajejo enotnega zaključka. Nekatere kažejo, da otroci ob lutki podajo več podatkov, a manj natančno, spet druge opozarjajo, da je uporaba lutk zaradi otrokovega nerazumevanja, da je lutka tako objekt kot reprezentacija njega, vprašljiva (Lamb idr., 2008). Pripomočki, kot je lutka, katero v razgovoru kdaj uporabljajo klinični psihologi, so se v nekaterih situacijah pokazali tudi kot distraktor, zaradi katerega je otrok podal več napačnih informacij (Melinder idr., 2010).

\section{Uporabnost v praksi}

Ob nizanju značilnosti otrokovega razvoja smo sproti omenjali tudi priporočljiv pristop k vodenju forenzičnega razgovora. Znova nanizajmo nekatere pomembnejše in konkretnejše usmeritve.

Da bi spodbudili prosti priklic in zmanjšali količino napak, je v forenzičnem razgovoru z otrokom priporočljivo uporabljati vprašanja odprtega tipa, na primer »Povej mi vse, česar se spominjaš.«. Dodatne podrobnosti je prav tako dobro spodbuditi s podvprašanji odprtega tipa »Kaj se je zgodilo potem?« ali »Povej mi še kaj o tem.«. Otroka lahko po dodatnih podatkih povprašamo tudi na podlagi že poznanih elementov, na primer $»$ Rekel si, da se te je ta in ta dotikal. Povej mi še kaj o tem.« (Lamb idr., 2008).

Včasih je treba vprašanja tudi ponoviti. Da s tem otroku ne bi dali občutka, da s prvim odgovorom nismo zadovoljni, in tako vplivali na njegov naslednji odgovor, 
ga moramo na to opozoriti: »Neko vprašanje bi ti rada zastavila še enkrat, ker sem zbegana. To ne pomeni, da moraš spremeniti svoj odgovor. Povej mi, česar se zares spomniš.» (Saywitz in Lyon, 2002.) Bistvo forenzičnega razgovora je namreč, kako se otroka izpraša in ne kolikokrat (Fivush, Peterson in Schwartzmueller, 2002). Da bi izboljšali prosti priklic, je mogoče uporabiti tudi praktične vaje, ki jih uporabimo kot model za poznejši pogovor o preiskovanih dogodkih. Otroka se na primer vpraša o nekem preteklem dogodku, da bi razumel, kaj se od njega v razgovoru pričakuje - torej priklic informacij o tem dogodku s čim manj pomoči specifičnih vprašanj izpraševalca (Saywitz in Lyon, 2002).

Izpraševalec mora otroka ustrezno pripraviti na svojo vlogo. Povedati mu mora, da sam ne pozna vseh odgovorov, ter ga spodbuditi, da izpraševalca popravi, če se z njim ne strinja. Sugestibilnosti in domišljijskim odgovorom se je predvsem pri otrocih $\mathrm{v}$ zgodnjem otroštvu treba ogniti tudi $z$ izogibanjem vprašanjem tipa »Poskusi si zamisliti, da ...« ali »Predstavljaj si, da ...«. Izpraševalec je manj sugestibilen, če na otroka ne pritiska, ne ponavlja zavajajočih vprašanj in ohranja otrokovo osredotočenost na njegove lastne izkušnje (Pipe, Lamb, Orbach in Esplin, 2004).

Da je med priporočili tudi izogibanje sugestibilnim vprašanjem, najbrž ni treba posebej poudarjati. Ubesediti jih je mogoče tudi drugače (uporabiti na primer $k a j, k d o$, kje, kakšen) in namesto »Rekel si, da je nosil jakno. Je bila rdeča ali modra?« vprašati »Rekel si, da je nosil jakno. Kakšne barve je bila?« (Saywitz in Lyon, 2002). Ob tem pa se je treba zavedati, da se težav s sugestibilnostjo ne da rešiti le $z$ vprašanji odprtega tipa. Izpraševalec mora biti pozoren na to, ali je lahko prišlo do kontaminacije spominov $\mathrm{v}$ času pred formalnim razgovorom, otroku mora mu postavljati čim manj dvoumna vprašanja, njegovo pozornost pa ohranjati pri ključni temi in mu dati možnost, da pojasni, od kod izvira določen spomin (Poole in Lindsay, 2002).

Da bi bil forenzični razgovor čim zanesljivejši, so v pomoč tudi navodila, podana pred razgovorom. Otroku pred intervjujem na primer rečemo: »Povej resnico. Ne izmišljuj si, ne ugibaj, « in s tem poudarimo pomen resnice. Pogosto se izpraševalci $v$ ta namen $\mathrm{z}$ otrokom pogovorijo tudi o tem, kaj resnica in laž pomenita (Saywitz in Lyon, 2002).

\section{Zaključek}

Poznavanje razvojne psihologije in specifične raziskave s področja pridobivanja informacij o preteklih dogodkih jasno kažejo, da so otroci lahko zanesljive priče, čeprav $\mathrm{v}$ praksi ni vedno tako. Na to opozarja tudi naslov enega redkih prispevkov na to temo pri nas: Kako dobre priče so zlorabljeni otroci ali kako dobri spraševalci so preiskovalci (Umek, 2009). Sposobnost otrok, da so pri pričanju natančni, je namreč odvisna od kvalitete uporabljenih izpraševalskih tehnik (London, 2001). Specifična usposabljanja posameznikov, ki vodijo forenzične razgovore $\mathrm{z}$ otroki, so zato nujna. Ta bi morala biti teoretična in praktična, kot poudarja Umek (2009) pa tudi kontinuirana. Taka izobraževanja omogočajo osvežitev in poglabljanje znanja, v tem okviru pa so potrebne tudi supervizije, ki imajo poleg edukativnega še razbremenilni pomen.

\section{Literatura}

Aldridge, M. in Wood, J. (1997). Talking about feelings: Young children's ability to express emotions. Child Abuse \& Neglect, 21(12), 1221-1233.

Bahrick, L., Parker, J., Fivush, R. in Levitt, M. (1998). The effects of stress on young children's memory for a natural disaster. Journal of Experimental Psychology: Applied, 4(4), 308-331.

Berk, L. E. (2006). Child development. Boston: Pearson.

Carpendale, J., Lewis, C., Susswein, N. in Lunn, J. (2009). Talking and thinking: The role of speech in social understanding. V A. Winsley, C. Fernyhough in I. Montero (ur.), Executive functioning, and the development of verbal self-regulation (str. 83-94). Cambridge: Cambridge University Press.

Carter Imhoff, M. in Baker-Ward, L. E. (2002). Memory. V N. J. Salkind (ur.), Child development (str. 255260). New York: Macmillan Reference USA.

Evans, A. D. in Lee, K. (2010). Promising to tell the truth makes 8- to 16-year-olds more honest. Behavioral Sciences and the Law, 28(6), 801-811.

Fivush, R., Peterson, C. in Schwartzmueller, A. (2002). Questions and answers: The credibility of child witnesses in the context of specific questioning techniques. V M. L. Eisen, J. A. Quas in G. S. Goodman (ur.), Memory and suggestibility in forensic interview (str. 331-354). Mahwah: Taylor \& Francis e-Library.

Fivush, R. in Reese, E. (2002). Reminiscing and relating: The development of parent-child talk about the past. V J. D. Webster in B. K. Height (ur.), Critical advances in reminiscence work: From theory to application (str. 109-122). New York: Springer.

Garber, B. D. (2009). Developmental psychology for family law professional: Theory, application, and the best interests of the child. New York, NY, ZDA: Springer.

Goodman, G. S., Quas, J. A., Batterman-Faunce, J. M., Riddlesberger, M. M. in Kuhn, J. (1997). Children's reactions to and memory for a stressful event: Influences of age, anatomical dolls, knowledge, and parental attachment. Applied Developmental Science, 1(2), 54-75.

Hershkowitz, I., Orbach, Y., Lamb, M. E., Katz, C. in Horowitz, D. (2012). The development of communicative and narrative skills among preschoolers: Lessons from forensic interviews about child abuse. Child Development, 83(2), 611-622. 
Hunt, J. S. in Borgida, E. (2001). Is that what I said? Witnesses' responses to interviewer modifications. Law and Human Behavior, 25(6), 583-603.

Jamison, L. (n. d.). Common Childhood Fears. Pridobljeno na http://cpancf.com/articles_files/COMMON_ CHILDHOOD_FEARS.asp

Kavčič, T. in Fekonja, U. (2004). Čustveni razvoj v zgodnjem otroštvu. V L. Marjanovič Umek in M. Zupančič (ur.), Razvojna psihologija (str. 291-314). Ljubljana: Založba Rokus.

Lamb, M. E. in Brown, D. A. (2006). Conversational apprentices: Helping children become competent informants about their own experiences. British Journal of Developmental Psychology, 24(1), 215-234.

Lamb, M. E., Hershkowitz, I., Orbach, Y. in Esplin, P. E. (2008). Tell me what happened. Structured investigative interviews of child victims and witnesses. West Sussex: Wiley.

Lippert, T., Cross, T. P., Jones, L. in Walsh, W. (2009). Telling interviewers about sexual abuse: Predictors of child disclosure at forensic interviews. Child Maltreatment, 14(1), 100-113.

London, K. (2001). Investigative interviews of children: A review of psychological research and implications for police practices. Police quarterly, 4(1), 123-144.

Marjanovič Umek, L. (2004). Spoznavni razvoj v zgodnjem otroštvu. V L. Marjanovič Umek in M. Zupančič (ur.), Razvojna psihologija (str. 291-314). Ljubljana: Založba Rokus.

Melinder, A., Alexander, K., Cho, Y. I., Goodman, G. S., Thoresen, C., Lonnum, K. in Magnussen, S. (2010). Children's eyewitness memory: A comparison of two interviewing strategies as realized by forensic professionals. Journal of Experimental Child Psychology, 105(3), 156-177.

Midaeva, E. K. in Lyubimova, Z. V. (2008). Formation of language-specific characteristics of speech sounds in early ontogeny. Human Physiology, 34(5), 649-652.

Müller, U., Jacques, S., Brocki, K. in Zelazo, P. D. (2009). The executive functions of language in preschool children. V A. Winsley, C. Fernyhough in I. Montero (ur.), Executive functioning, and the development of verbal self-regulation (str. 53-41). Cambridge: Cambridge University Press.

Olaffson, E. (2007), Children's memory and suggestibility. $\mathrm{V}$ K. C. Faller (ur.), Interviewing children about sexual abuse: Controversies and best practice (str. 10-34). New York: Oxford University Press.

Ornstein, P. A. in Haden, C. A. (2002). The development of memory: Toward an understanding of children's testimony. V M. L. Eisen, J. A. Quas in G. S. Goodman (ur.), Memory and suggestibility in forensic interview (str. 29-62). Mahwah: Taylor \& Francis e-Library.

Papalia, D. E., Olds, S. W. in Feldman, R. D. (2003). Otrokov svet: Otrokov razvoj od spočetja do konca mladostništva. Ljubljana: Educy.
Perry, B. D. in Pollard, D. (1997, oktober). Altered brain development following global neglect in early childhood. Predstavitev na Annual meeting of the Society For Neuroscience: Proceedings from Annual Meeting, New Orleans. Pridobljeno na https:/childtrauma.org/wp-content/uploads/2013/12/ PerryPollard_SocNeuro.pdf

Peterson, C. (2012). Children's autobiographical memories across the years: Forensic implications of childhood amnesia and eyewitness memory for stressful events. Developmental Review, 32(3), 287-306.

Pipe, M., Lamb, M. E., Orbach, Y. in Esplin, P. W. (2004). Recent research on children's testimony about experienced and witnessed events. Developmental Review, 24(4), 440-468.

Poole, D. A. in Lindsay, D. S. (2002). Children's suggestibility in the forensic context. V M. L. Eisen, J. A. Quas in G. S. Goodman (ur.), Memory and suggestibility in forensic interview (str. 355-381). Mahwah, NJ, ZDA: Taylor \& Francis e-Library.

Quas, J. A., Davis, E. L., Goodman, G. S. in Myers, J. E. (2007). Repeated questions, deception, and children's true and false reports of body touch. Child Maltreatment, 12(1), 60-67.

Quas, J. A., Goodman, G. S., Ghetti, S. in Redlich, A. D. (2000). Questioning the child witness: What can we conclude from the research thus far? Trauma, Violence and Abuse, 1(3), 223-249.

Ruck, M. D. (1996). Why children think they should tell the truth in court: Developmental considerations for the assessment of competency. Legal and Criminological Psychology, 1(1), 103-116.

Saywitz, K. J. in Lyon, T. D. (2002). Coming to grips with children's suggestibility. V M. L. Eisen, J. A. Quas in G. S. Goodman (ur.), Memory and suggestibility in forensic interview (str. 85-113). Mahwah: Taylor \& Francis e-Library.

Shaffer, D. R. in Kipp, K. (2010). Developmental psychology: Childhood and adolescence. Belmont: Wadsworth.

Subbotsky, E. (2010). Magic and the mind: Mechanisms, functions, and development of magical thinking and behavior. New York, NY, ZDA: Oxford University Press.

Talwar, V. in Lee, K. (2008). Social and cognitive correlates of children's lying behavior. Child development, 79(4), 866-881.

Tang, C. M. (2006). Developmentally sensitive forensic interviewing of preschool children: Some guidelines drawn from basic psychological research. Criminal Justice Review, 31(2), 132-145.

Umek, P. (2009). Kako dobre priče so zlorabljeni otroci ali kako dobri spraševalci so preiskovalci. Revija za kriminalistiko in kriminologijo, 60(1), 16-24.

Warren, A. R., Woodall, C. E., Hunt, J. S. in Perry, N. W. (1996). "It sounds good in theory, but...": Do investigative interviewers follow guidelines based on memory research? Child Maltreatment, 1(3), 231-245. 
Wilson, J. C. in Powell, M.(2001). A guide to interviewing children: Essential skills for counsellors, police, lawyers and social workers. Crows Nest: Allen \& Unwin.

Xu, F., Bao, X., Fu, G., Talwar, V. in Lee, K. (2010). Lying and truth-telling in children: From concept to action. Child Development, 81(2), 581-596.

Zorić, J. (2008). Vođenje forenzičnog intervjua: Postupni intervju. V J. Zorić (ur.), Forenzični intervju s djetetom (str. 59-87). Zagreb: Hrvatsko psihološko društvo.

Zupančič, M. (2004a). Socialni razvoj dojenčka in malčka. V L. Marjanovič Umek in M. Zupančič (ur.), Razvojna psihologija (str. 291-314). Ljubljana: Založba Rokus.

Zupančič, M. (2004b). Razvoj čustev in temperament ter osebnost $\mathrm{v}$ obdobjih dojenčka in malčka. V L. Marjanovič Umek in M. Zupančič (ur.), Razvojna psihologija (str. 291-314). Ljubljana: Založba Rokus. 